\title{
The left ventricular assist device as a patient monitoring system
}

\author{
Francesco Moscato $^{1,2,3}$, Christoph Gross ${ }^{1,2}$, Martin Maw ${ }^{1,2,4}$, Thomas Schlöglhofer ${ }^{1,2,4}$, Marcus Granegger ${ }^{4}$, \\ Daniel Zimpfer ${ }^{4}$ Heinrich Schima ${ }^{1,2,4}$
}

${ }^{1}$ Center for Medical Physics and Biomedical Engineering, Medical University of Vienna, Vienna, Austria; ${ }^{2}$ Ludwig Boltzmann Institute for Cardiovascular Research, Vienna, Austria; ${ }^{3}$ Austrian Cluster for Tissue Regeneration, Vienna, Austria; ${ }^{4}$ Division of Cardiac Surgery, Medical University of Vienna, Vienna, Austria

Correspondence to: Francesco Moscato, PhD. Center for Medical Physics and Biomedical Engineering, Medical University of Vienna, Waehringer Guertel 18-20, AKH-4L, 1090 Vienna, Austria. Email: francesco.moscato@meduniwien.ac.at.

\begin{abstract}
Technological progress of left ventricular assist devices (LVADs) towards rotary blood pumps and the optimization of medical management contributed to the significant improvements in patient survival as well as LVAD support duration. Even though LVAD therapy is now well-established for end-stage heart failure patients, the long-term occurrence of adverse events (AE) such as bleeding, infection or stroke, still represent a relevant burden. An early detection of $\mathrm{AE}$, before onset of major symptoms, can lead to further optimization of patient treatment and thus mitigate the burden of AE. Continuous patient monitoring facilitates identification of pathophysiological states and allows anticipation of AE to improve patient management. In this paper, methods, algorithms and possibilities for continuous patient monitoring based on LVAD data are reviewed. While experience with continuous LVAD monitoring is currently limited to a few centers worldwide, the pace of developments in this field is fast and we expect these technologies to have a global impact on the well-being of LVAD patients.
\end{abstract}

Keywords: Left ventricular assist device (LVAD); patient monitoring; hemodynamics; adverse events (AE)

Submitted Oct 19, 2020. Accepted for publication Dec 15, 2020.

doi: 10.21037/acs-2020-cfmcs-218

View this article at: http://dx.doi.org/10.21037/acs-2020-cfmcs-218

\section{Introduction}

Left ventricular assist devices (LVADs) are the current therapy of choice for end-stage heart failure, as a bridge to heart transplantation or for permanent use (1). A tremendous improvement in patient survival has been achieved since the first introduction of LVADs. One-year survival improved from $52 \%$ with first-generation pulsatile devices (2) to $82 \%$ with currently used continuous-flow LVADs (1). However, new challenges for this therapy have become evident with longer LVAD support durations. The burden of adverse events (AE), such as gastrointestinal (GI) bleeding, infection, stroke and right heart failure, were highlighted in the $5^{\text {th }}$ Intermacs report in 2013, which showed a freedom from major adverse event or death of just $30 \%$ by the first year after implantation (3). More recent data show a freedom from readmission at one year of $21-$ $23 \%$ (4).
Thus, further technological advances and improved patient management have become necessary to enhance the quality of life of LVAD patients, or even to extend the treatment to less advanced stages of heart failure. The recent introduction of fully-magnetically levitated technologies has led to a reduced incidence of major AE. Particularly, the unadjusted first-year freedom from cerebrovascular accidents improved from $86 \%$ to $93 \%$. The cumulative number of rehospitalizations in the whole patient population is, however, still high, with 218 rehospitalizations per 100 patients by twelve months (1). A possible way to reduce the burden of $\mathrm{AE}$ is to anticipate them by recognizing the initial derangement that leads to major consequences and to act early to change patient treatment.

Patient monitoring devices and software tools have the potential to provide early recognition of $\mathrm{AE}$ and thereby lead to an improvement in patient care (5). For 


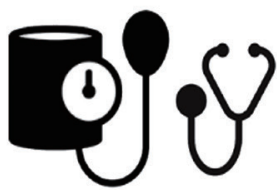

Manometer / tonometer

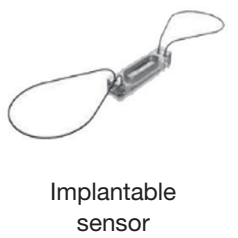

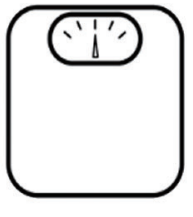

Scale

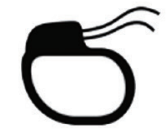

ICD/Pacemaker

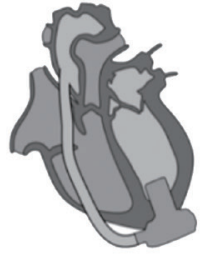

LVAD

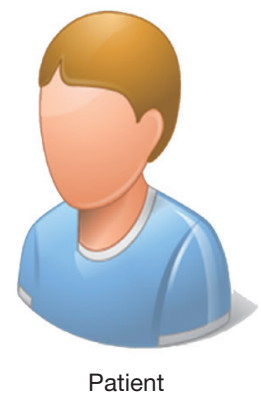

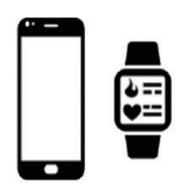

Mobile phone/ activity tracker

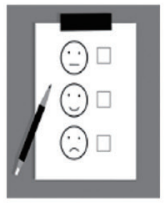

Patient interview

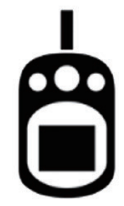

INR-monitor

Figure 1 Possible data sources for LVAD patient monitoring. LVAD, left ventricular assist device; ICD, implantable cardioverterdefibrillator; INR, international normalized ratio.

example, wireless pulmonary artery monitoring resulted in a reduction of heart failure hospitalizations and more frequent changes in medications in the active monitoring group compared to the control group (6,7). Multi-sensor data integration and analysis from cardiac resynchronization therapy devices could predict heart failure events up to thirty-four days before patient presentation (8). While the technological possibilities for LVAD patient monitoring have been proposed and discussed since the early days of continuous-flow LVADs (9-12), it is only recently that monitoring has received increasing attention from the clinical community $(13,14)$.

Data for LVAD patient monitoring can be acquired from a variety of sources (Figure 1), including external devices such as point-of-care international normalized ratio (INR) monitors $(15,16)$, or from implantable devices such as cardioverter-defibrillators (ICD)/pacemakers (17), left atrial pressure sensors (18) and pulmonary artery pressure sensors (19). There have also been developments to include sensors directly into the LVAD system. The pump flow rate sensor has been implemented in one of the first continuousflow LVADs (20) and has been used since then for patient monitoring. More recently sensors to measure ventricular pressure (21) or volume (22), as well as electrocardiography sensing (23), have been embedded in the LVAD inflow cannula and evaluated in various experimental settings. These sensors are not yet part of clinically available devices.
Structured telephone interviews also constitute a relatively accessible source of data that can lead to significant improvements in outcome (24). Arterial blood pressure measurement devices (25), acoustic measurements $(26,27)$ and weighing scales can provide sources of relevant information. Finally, mobile phone apps (28) and activity trackers $(29,30)$ provide a potential for patient monitoring, especially as they support the patients self-monitoring. This may improve patient compliance as the technology may be able to support important tasks, such as adjustment of anticoagulation therapy (31). In this work, the current possibilities of LVAD patient monitoring are summarized, with a particular focus on data available from the LVAD itself that permit continuous monitoring of patient hemodynamics in the out-of-hospital setting, without the need for additional sensors.

\section{LVAD data for patient monitoring}

The LVAD pumps blood by transferring rotational kinetic energy into hydrodynamic energy of the fluid flow. The driving torque is generated by an electric motor, usually powered by batteries. In order to ensure proper rotational speed control, the motor current, voltage and impeller speed have to be measured and are therefore available for further processing. Whilst these device measurements seem at a first glance to be unrelated to patient hemodynamics, 


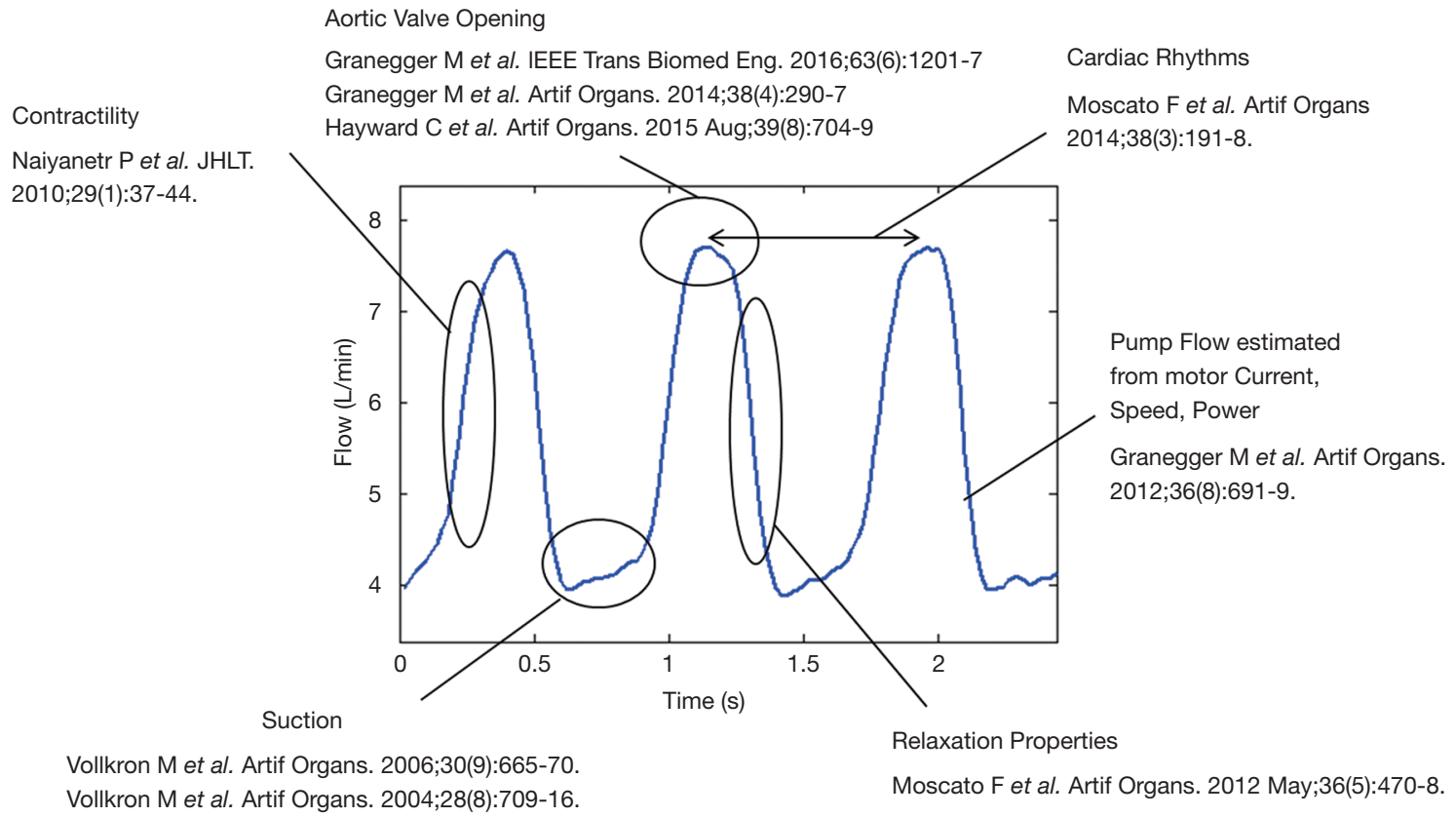

Figure 2 The LVAD flow waveform derived from motor current, speed and power and the hemodynamic data that can be estimated from it. LVAD, left ventricular assist device.

in reality they provide the basic elements to estimate the flow-rate through the pump (32), which in turns reflects the interaction between the LVAD, the assisted ventricle and the vascular system. Over the course of at least the last fifteen years, methods and algorithms have been developed to estimate relevant hemodynamic variables from the pumpavailable data (33-40). In Figure 2, a representative LVAD flow waveform is shown, with the physiological variables that can be derived from it.

\section{Data recorder device and clinical study for $24 / 7$ patient monitoring}

To access pump data from patients, a continuous data acquisition system (CDAS) was developed that records pump motor current, power and impeller speed from the HeartWare ventricular assist device (HVAD) controller (Medtronic plc, Minneapolis MN, USA) and stores them on an 8 GB micro-SD card (Figure $3 A$ ). Up to four weeks of waveform data can be stored with a time-resolution of 0.02 seconds. Connection to the HVAD pump controller is realized using an optical isolator to avoid any direct electrical linking. The small dimensions of the device $(100 \mathrm{~mm} \times 55 \mathrm{~mm} \times 30 \mathrm{~mm})$ allow fitting in the peripherals' bag (Figure 3B). The device also includes a tri-axial accelerometer for recording bag movements from which patient's activity (e.g., step count) can be inferred. Periodic download of data on a computer has to be performed for data processing.

LVAD-based monitoring tools were evaluated in a clinical study [ClinicalTrials.gov ID: NCT01981642 (41)]. Patients implanted with an HVAD device (Medtronic plc, Minneapolis MN, USA), who were over the age of eighteen, were enrolled in the clinical study. Patients received the CDAS in the General Hospital Vienna and were asked to keep it connected to the controller until exchange was necessary (i.e., approx. every four weeks). A database was developed with MATLAB (The Mathworks Inc., Natick, MA, USA) for analysis of large patient datasets. In addition to the HVAD data the advanced pump flow waveform features (Figure 2) were calculated and stored in the database, as well as the accelerometer data. In total, forty-two patients [age: 58.5 (33.6-71.0) y; body mass index: $26.9(21.8-37.0) \mathrm{kg} / \mathrm{m}^{2}$; both expressed as median $(5-$ 95 percentile); female gender: $14.3 \%$ ] received the CDAS for more than one day, and 9,201 recordings (each of up to $24 \mathrm{~h}$ ) were processed. The median duration of the available data recordings was 19.8 hours, with the $5^{\text {th }}$ to $95^{\text {th }}$ percentile of 7.7 to 23.6 hours. In the following sections, key findings from the study will be presented. 

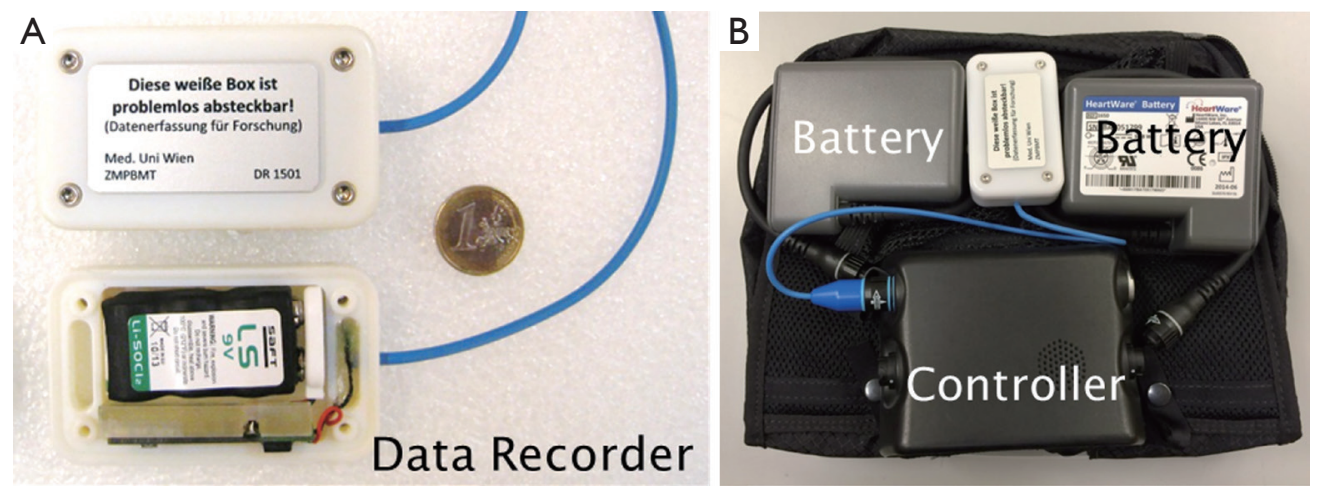

Figure 3 The LVAD data recorder developed at the Medical University of Vienna (A) and how it fits within the peripherals' carrying bag (B). LVAD, left ventricular assist device.

\section{Ventricular suction}

Ventricular wall collapse and suction occurs if drainage of blood by the LVAD exceeds venous return or if the pumps inflow cannula placement leads to suction of ventricular structures. Suction may lead to damage of the myocardial wall, may induce ventricular arrhythmias or may cause thromboembolic events, because of the disturbed blood flow pathways that arise during such abnormal pump operation. While this phenomenon has been the focus of attention since the early days of LVAD development $(11,34,42)$, it is only recently that observations of suction occurrence during the daily life of LVAD patients has been made. In Figure 4, a continuous recording of LVAD flow and patient activity over the course of three hours is depicted. During this period of time, the patient went home after a routine ambulatory visit. In the first part of the graph, one can observe a flow waveform without suction and a reduced pump flow pulsatility. Physical activity triggered an increase in both mean-flow and flow pulsatility. When the patient returned to previous levels of mean-flow and pulsatility, a long suction cluster ( $1 \mathrm{~h}$ duration) occurred.

These and similar observations (e.g., circadian behavior) are only possible with a continuous monitoring of pump data. For these initial observations, a systematic analysis of continuous pump data recordings from a subgroup of ten patients was performed. Patients were followed over a period of fifteen days after the first ambulatory visit post rehab-clinic discharge (43). Five patients showed highsuction (HS) rates with episodes ranging from 5\% to $40 \%$ suction beats of all beats in one hour, while the other five patients had $<5 \%$ suction/h throughout the observation period (low-suction, LS). Four out of five HS patients had ischemic heart failure etiology, whereas four out of five LS patients had dilatative etiology. Echocardiographic examinations revealed that the left ventricular end-diastolic diameter was smaller in the HS-patients compared to the LS-patients $(53.4 \pm 8.7$ vs. $71.0 \pm 8.5 \mathrm{~mm}, \mathrm{P}=0.018)$. Despite the small number of patients, this study showed, for the first time, that suction can be a concern even in patients that are supposed to be optimally adjusted and clinically stable. Additionally, the study suggested that left ventricular chamber dimensions and intracardiac LVAD position might contribute to an increased occurrence of suction. Evaluation in a larger patient cohort is necessary to confirm these findings, however, these first observations are already very compelling.

\section{Cardiac rhythms}

The heart rate, its variability, and in particular arrhythmias, bear important information about the cardiac and overall patient condition (44). Continuous monitoring of cardiac rhythms can be done if the LVAD patient has also an ICD/ pacemaker implanted (45), however, it is the combination of both cardiac rhythms and pump data that can lead to a deeper understanding of the relationship between and arrhythmic events and hemodynamic derangements [e.g., when suction occurs $(43,46)]$. In Figure 5, two examples of ECG-tracings juxtaposed to pump flow waveform are shown. It is worth noting that ventricular suction is present before, during and after the tachycardia event.

Suction can either induce tachycardia or even occur as a result from tachycardia. To shed some light into these mechanisms the occurrence of tachycardia (defined as at 


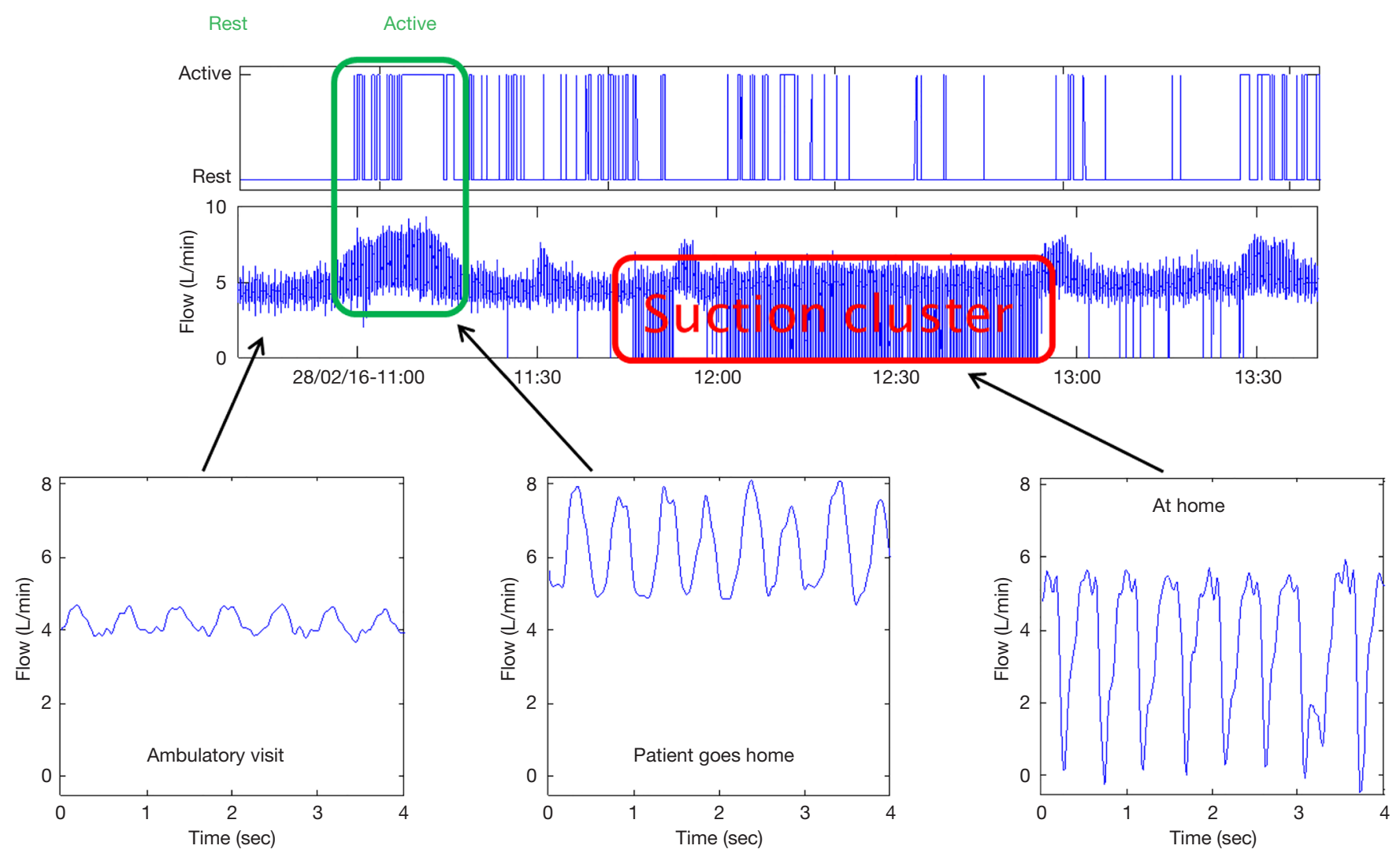

Figure 4 In the upper panel, both activity and pump flow from a patient are shown over the course of about three hours. Below detail view: (four-second windows) of the pump flow at three time points when the patient was being visited in the hospital (below left), when the patient went home (below middle), and when the patient was at home (below right).

least 5 consecutive beats with heart rate $>100 \mathrm{bpm}$ ) before, during and after suction periods of different durations were evaluated in the same patient collective reported in reference (43). In Figure 6, results are shown in form of pie charts; $15.5 \% \pm 3.8 \%$ of suction periods showed an association with cardiac arrhythmia (labels IIO, IOI, OII, IOO, OIO, OOI). As the suction duration increases, tachycardia becomes more important: tachycardia precedes suction (all labels beginning with I) $57 \%$ of the time when suction is sustained ( $>5 \mathrm{~min}$ duration). Further analysis is needed to elucidate the causal mechanisms; it seems, however, that it is reasonable to say that whenever sustained arrhythmia is present the presence of suction should be investigated.

\section{Exercise capacity, daily life activity and adverse events}

Monitoring of LVAD data can improve the understanding of hemodynamic unloading and the interaction between the assisted heart and the LVAD in response to exercise. With current LVADs driven at constant speed, an increase in preload typically results in a modest increase in pump flow during exercise $(47,48)$. The major response to increased perfusion demands is due to an increase in heart rate and ventricular ejection towards the aortic valve, both of which can be quantified during exercise using LVADbased monitoring (49). Chronotropic incompetence or heart rate recovery immediately after exercise can be also easily monitored. Heart rate recovery, in particular, has been shown to be a predictor of clinical outcome and mortality $(50,51)$.

While exercise capacity of LVAD patients has been extensively investigated (52-54) less is known about daily patient activity and how this could be utilized to better understand the impact of $\mathrm{AE}$ on patient well-being or even to anticipate/predict them. In Figure 7, two exemplary cases show the amount of steps/day from patients over the course 


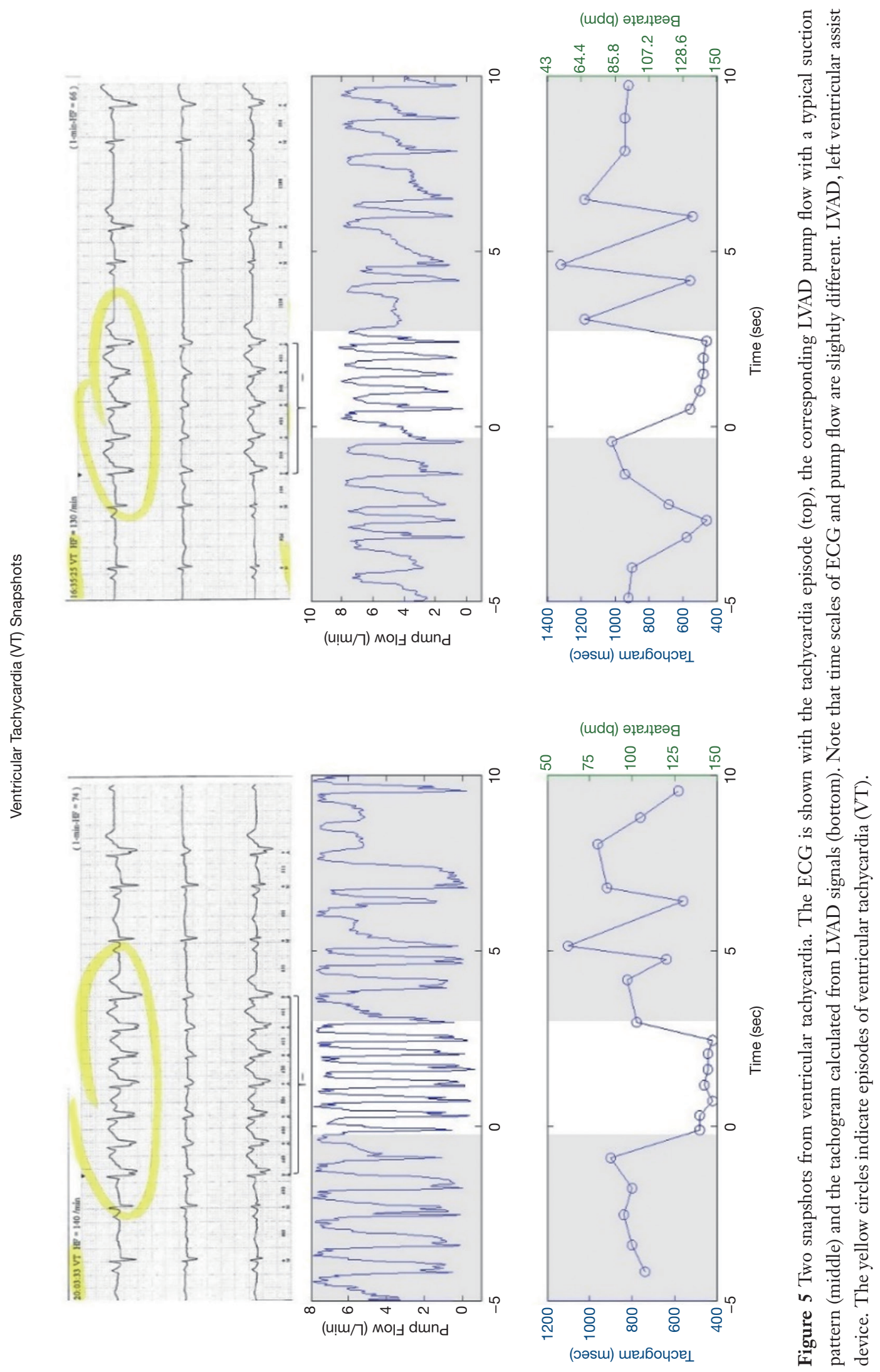


$\mathrm{HR}>100 \mathrm{bpm}$ for at least 5 consecutive beats

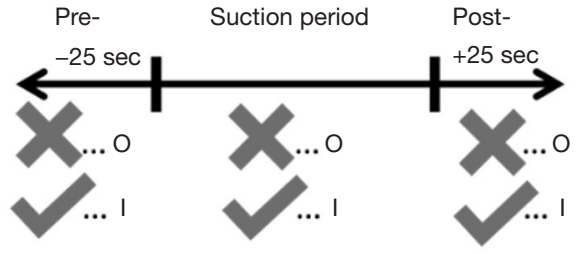

Suction period duration
Labels "O/I"

indicate tachycardia

absence/presence
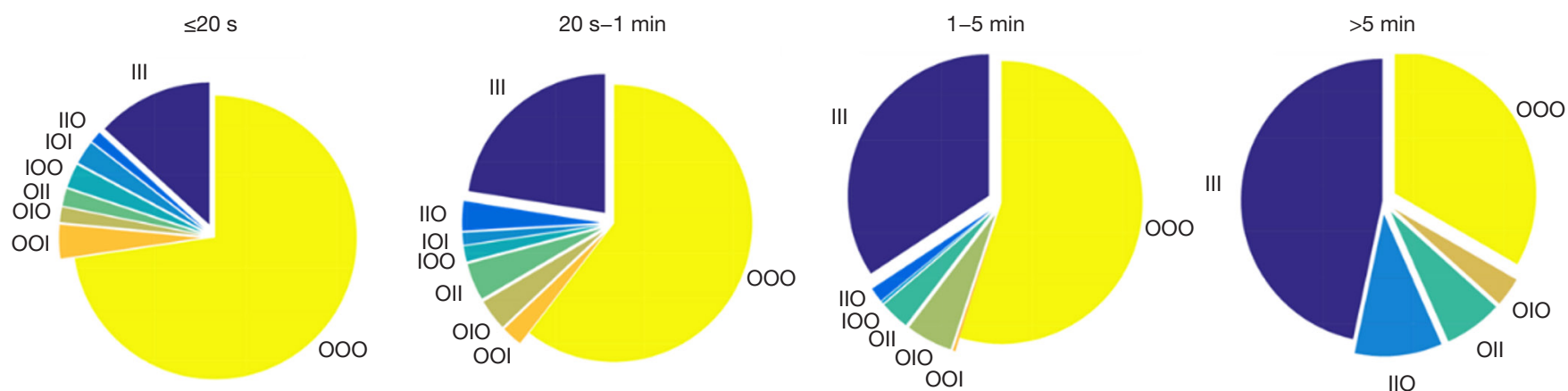

Figure 6 Association between suction and tachycardia. The four pie charts show if tachycardia was present before, during and after suction periods of different duration (ranging from $\leq 20 \mathrm{~s}$ to $>5 \mathrm{~min}$ ).

A (1) Major Bleeding (POD 74)

(2) Maj. Bleed., Neurol. Dysf. (POD 164)

(3) Maj. Infection (POD 328)

(4) Maj. Infection non-device related (POD 380)

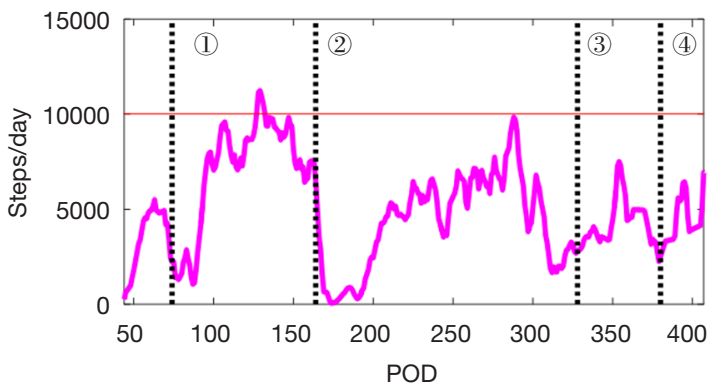

B

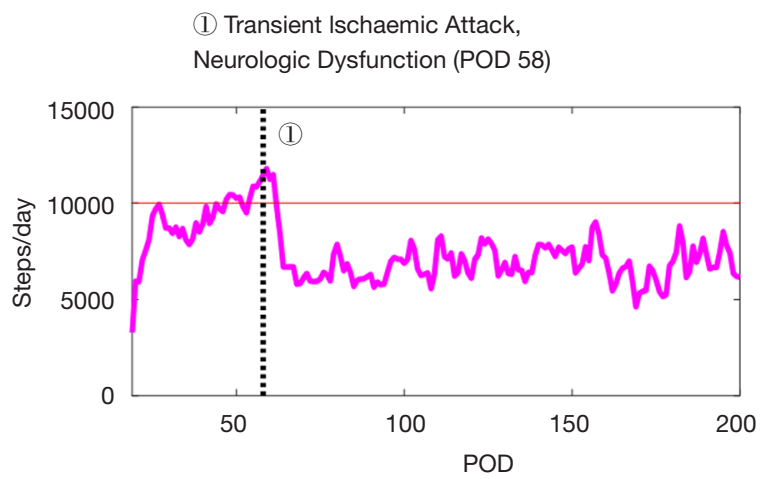

Figure 7 Two exemplary cases of how daily activity from patients who suffered from adverse events changed before and after rehospitalization. POD, post-operative day.

of about one year after LVAD implantation. The first of the two patients (Figure $7 A$ ) had to be rehospitalized four times. It is interesting to note how the activity started declining already 50 days before readmission for a major infection (marker number 3). The second case (Figure $7 B$ ) shows, on the other hand, that activity after a transient ischemic attack for this patient never returned to the pre-event level.

The combined analysis of exercise tests responses and daily life activity might help to identify differences in patients, particularly with regard to their cardiac function reserve (55).

\section{Trend data analysis}

High time-resolution data provide an extremely granular level of detail, with the possibility to observe even single- 


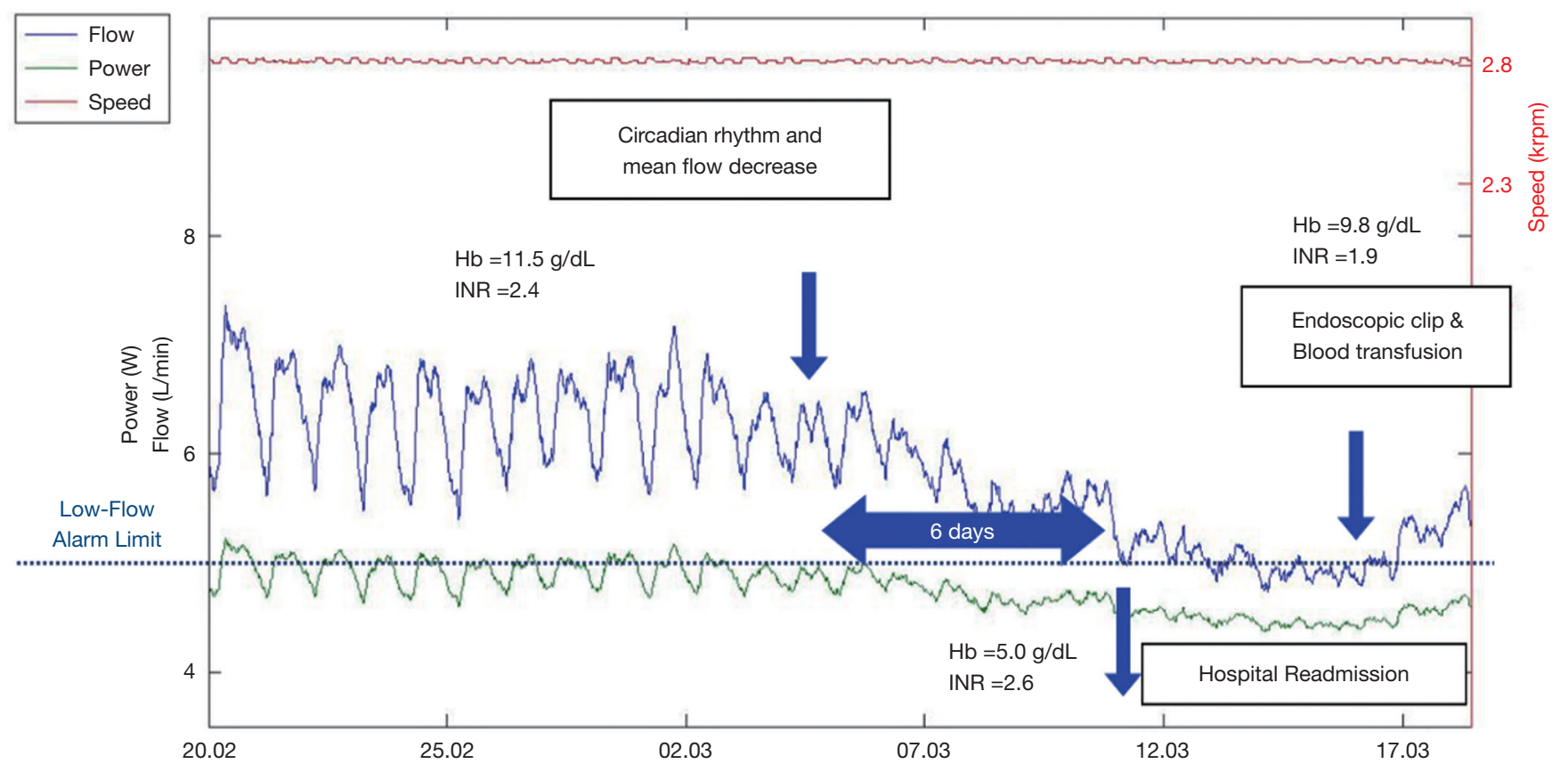

Figure 8 Trend data analysis in a patient that had to be readmitted because of GI bleeding. GI, gastrointestinal; Hb, hemoglobin; INR, international normalized ratio.

beat events. However, these data are not generally available in commercial devices yet. The analysis of so-called logfiles, which are pump data sampled at time intervals in the range of minutes to hours, is available in most devices and it has a potential to quickly translate into patient treatment improvements. Trend analyses of the pump signals can indeed indicate both patient recovery but also dysfunction. Increase of circadian variation of LVAD flow has been shown as a sign of post-operative recovery of cardiovascular endorgan function and improved sympathovagal balance (56). On the other hand, the decrease of circadian variations has been associated to thrombotic events, potentially anticipating clinical manifestation by $12 \pm 6$ days (57). Pump thrombosis can also be observed and managed with the help of log-file analysis of average motor power data (58-60). A steady decrease of pump flow together with a progressive disappearance of circadian rhythm can be also indicative of GI bleeding and resulting hypovolemia, as shown in Figure 8.

The developed methods and algorithms presented so far can be also used in any LVAD for which pump data (motor current and speed at least) can be retrieved, or when a direct measurement of pump flow is available. An initial clinical experience of patient telemonitoring with LVADs with an embedded pump flow sensor (Heart Assist 5 and the aVAD, ReliantHeart Inc., Houston, TX, USA) has been reported in (61). Here, eleven patients were observed using the available telemonitoring tool over an average follow-up time of $221.6 \pm 158.1$ days. Both flow waveform and trenddata analysis allowed timely recognition of abnormalities such as pump thrombosis and hypovolemia.

\section{Translating pump monitoring to better patient outcomes}

The diagnostic possibilities arising from waveform and trend analysis of pump data are clearly not limited to the one presented here, and we anticipate that much more applications will come in the near future. The analysis of pump signals and how these correlate to $\mathrm{AE}$ and/or physiologically relevant states is only the first step. The integration of LVAD data with a variety of other available data (Figure 1) appears to be the natural following step. This could also include the fusion with data provided by sensors integrated in future LVADs. Sensors integrated in the LVAD to measure ventricular pressure or volume would be very valuable in assessing the supported heart function, however reliability and/or long-term stability issues might 


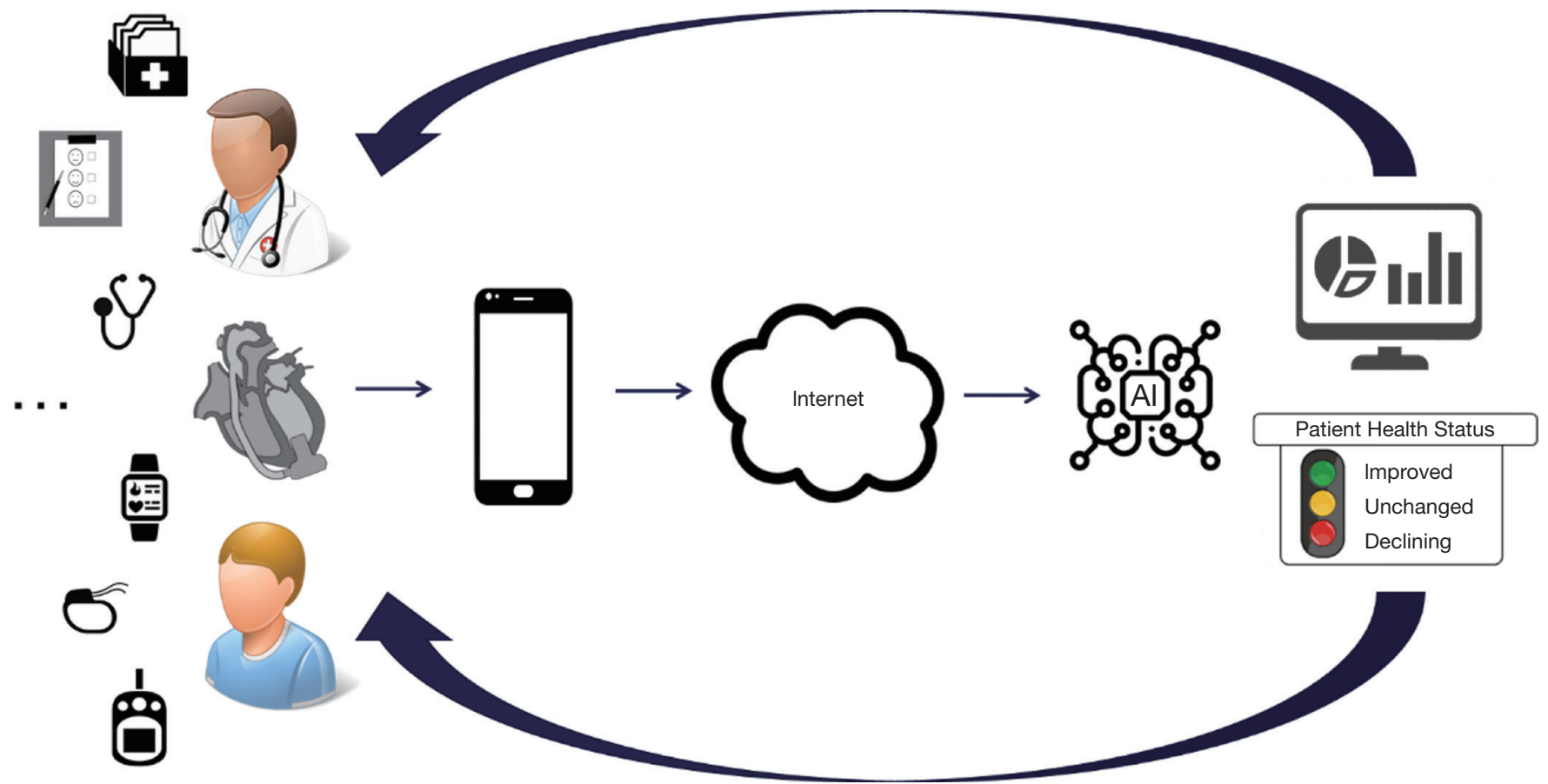

Figure 9 Data integration, transfer and processing to provide feedback to both the physician and the patient.

limit their utility. Indeed, the more components and features a device has, the more probable it is that their failure occurs. Therefore, only a proper combination of pump-intrinsic signals as motor current/speed and additional integrated sensors for ventricular pressure/volume, will lead to reliable and clinically relevant pump and patient monitoring.

While innovation in pump monitoring provides additional information on patient status, interpretation of this data is the missing link to clinical implementation. Ultimately, intervention based on this data is the goal, not excellent hindsight. For this purpose, the newly gathered information has to be processed and ultimately distilled into actionable items for the clinician or the patient. In a first step, guidelines on interfacing with pump monitoring enables one to navigate the vast sea of information. Should a loss of circadian rhythm indicate a call to the caregiver? Is transient suction acceptable, or already trigger a call to the clinic? When should pump monitoring even be consulted? The pump monitoring tools do not inherently provide answers to these questions, but rather a means of observing previously unseen behavior, especially in the long times between patient visits to the outpatient clinic. Only increased experience with these tools will show their true utility. We believe that in the complex treatment of heart failure with LVADs, these tools of pump monitoring could save precious days or even weeks before intervention and help guide treatment strategy.

\section{Conclusions}

We live in a society that collects data at an unprecedented rate. In 2017, an estimate of the amount of unstructured data that a human being produces in a life time was 1,100 terabytes (62). This data typically comes from monitoring devices such as activity trackers or smart watches. In the same estimation, structured and labeled data, like these coming from electronic medical records, would account for 0.4 terabytes. We are currently extracting meaningful information for unstructured (e.g., LVAD) data, with use of human structured health records as a reference. It is, however, plausible to think of this process of data extraction, integration and interpretation as a process of teaching machines to support the diagnostic, prognostics and therapeutic skills of a physician, or even to directly feed-back information to a patient providing early warnings about underlying medical conditions (Figure 9). This ensures a vigilant system, without additional load on the caregiver. However, it is important that the additional 
information coming to the clinician or patient is signal, rather than noise.

While this scenario might seem still far away, the pace of developments in artificial intelligence has been accelerating in the past few years and we foresee that this will also have a significant impact on LVAD patients.

\section{Acknowledgments}

Funding: Parts of this research have been funded by the Austrian Science Fund (FWF-KLI357) and the Ludwig Boltzmann Institute for Cardiovascular Research.

\section{Footnote}

Conflicts of Interest: FM: Research Grant (Medtronic); TS: Consultant, Advisor (Abbott, Medtronic); Research Grant (Medtronic); MG: Consultant, Research Grants (BerlinHeart); DZ: Advisor, Proctor, Research Grants, nonfinancial Support, Speaker Fees (Abbott, Medtronic, Berlin Heart, Edwards); HS: Research Grant, Advisor (Medtronic). The other authors have no conflicts of interest to declare.

Open Access Statement: This is an Open Access article distributed in accordance with the Creative Commons Attribution-NonCommercial-NoDerivs 4.0 International License (CC BY-NC-ND 4.0), which permits the noncommercial replication and distribution of the article with the strict proviso that no changes or edits are made and the original work is properly cited (including links to both the formal publication through the relevant DOI and the license). See: https://creativecommons.org/licenses/by-nc-nd/4.0/.

\section{References}

1. Teuteberg JJ, Cleveland JC, Cowger J, et al. The Society of Thoracic Surgeons Intermacs 2019 Annual Report:

The Changing Landscape of Devices and Indications. Ann Thorac Surg 2020;109:649-60.

2. Rose EA, Gelijns AC, Moskowitz AJ, et al. Long-Term Use of a Left Ventricular Assist Device for End-Stage Heart Failure. N Engl J Med 2001;345:1435-43.

3. Kirklin JK, Naftel DC, Kormos RL, et al. Fifth INTERMACS annual report: risk factor analysis from more than 6,000 mechanical circulatory support patients. J Heart Lung Transplant 2013;32:141-56.

4. Kormos RL, Cowger J, Pagani FD, et al. The Society of Thoracic Surgeons Intermacs Database Annual
Report: Evolving Indications, Outcomes, and Scientific Partnerships. Ann Thorac Surg 2019;107:341-53.

5. Raj LM, Saxon LA. Haemodynamic Monitoring Devices in Heart Failure: Maximising Benefit with Digitally Enabled Patient Centric Care. Arrhythm Electrophysiol Rev 2018;7:294-8.

6. Abraham WT, Adamson PB, Bourge RC, et al. Wireless pulmonary artery haemodynamic monitoring in chronic heart failure: a randomised controlled trial. Lancet 2011;377:658-66.

7. Costanzo MR, Stevenson LW, Adamson PB, et al. Interventions Linked to Decreased Heart Failure Hospitalizations During Ambulatory Pulmonary Artery Pressure Monitoring. JACC Heart Fail 2016;4:333-44.

8. Boehmer JP, Hariharan R, Devecchi FG, et al. A Multisensor Algorithm Predicts Heart Failure Events in Patients With Implanted Devices: Results From the MultiSENSE Study. JACC Heart Fail 2017;5:216-25.

9. Schima $\mathrm{H}$, Trubel W, Moritz A, et al. Noninvasive monitoring of rotary blood pumps: necessity, possibilities, and limitations. Artif Organs 1992;16:195-202.

10. Holzer S, Scherer R, Schmidt C, et al. A clinical monitoring system for centrifugal blood pumps. Artif Organs 1995;19:708-12.

11. Konishi H, Antaki JF, Amin DV, et al. Controller for an Axial Flow Blood Pump. Artif Organs 1996;20:618-20.

12. Yu YC, Boston JR, Simaan MA, et al. Minimally invasive estimation of systemic vascular parameters. Ann Biomed Eng 2001;29:595-606.

13. Potapov EV, Antonides C, Crespo-Leiro MG, et al. 2019 EACTS Expert Consensus on long-term mechanical circulatory support. Eur J Cardiothorac Surg 2019;56:230-70.

14. Veenis JF, Brugts JJ. Remote monitoring for better management of LVAD patients: the potential benefits of CardioMEMS. Gen Thorac Cardiovasc Surg 2020;68:209-18.

15. Heneghan C, Ward A, Perera R, et al. Self-monitoring of oral anticoagulation: systematic review and meta-analysis of individual patient data. Lancet 2012;379:322-34.

16. Schlöglhofer T, Zapusek L, Wiedemann D, et al. International Normalized Ratio Test Frequency in Left Ventricular Assist Device Patients Affects Anticoagulation Quality and Adverse Events. ASAIO J 2021;67:157-62.

17. Rosenbaum AN, Kremers WK, Duval S, et al. Arrhythmias in Patients with Cardiac Implantable Electrical Devices after Implantation of a Left Ventricular Assist Device. ASAIO J 2016;62:274-80. 
18. Hubbert L, Baranowski J, Delshad B, et al. Left Atrial Pressure Monitoring With an Implantable Wireless Pressure Sensor After Implantation of a Left Ventricular Assist Device. Asaio J 2017;63:e60-5.

19. Veenis JF, Manintveld OC, Constantinescu AA, et al. Design and rationale of haemodynamic guidance with CardioMEMS in patients with a left ventricular assist device: the HEMO-VAD pilot study. ESC Heart Fail 2019;6:194-201.

20. Noon GP, Loebe M. Current status of the MicroMed DeBakey Noon Ventricular Assist Device. Tex Heart Inst J 2010;37:652-3.

21. Zhou MD, Yang C, Liu Z, et al. An implantable FabryPérot pressure sensor fabricated on left ventricular assist device for heart failure. Biomed Microdevices 2012;14:235-45.

22. Dual SA, Zimmermann JM, Neuenschwander J, et al. Ultrasonic sensor concept to fit a ventricular assist device cannula evaluated using geometrically accurate heart phantoms. Artif Organs 2019;43:467-77.

23. Her K, Ahn CB, Park SM, et al. Heart monitoring using left ventricle impedance and ventricular electrocardiography in left ventricular assist device patients. Biomed Eng Online 2015;14:25.

24. Schlöglhofer T, Horvat J, Moscato F, et al. A Standardized Telephone Intervention Algorithm Improves the Survival of Ventricular Assist Device Outpatients. Artif Organs 2018;42:961-9.

25. Granegger M, Thamsen B, Moscato F, et al. Noninvasive assessment of blood pressure in rotary blood pump recipients using a novel ultrasonic Doppler method. Int J Artif Organs 2019;42:226-32.

26. Kaufmann F, Hörmandinger C, Stepanenko A, et al. Acoustic spectral analysis for determining pump thrombosis in rotary blood pumps. ASAIO J Am Soc Artif Intern Organs 1992 2014;60:502-7.

27. Semiz B, Hersek S, Pouyan MB, et al. Detecting Suspected Pump Thrombosis in Left Ventricular Assist Devices via Acoustic Analysis. IEEE J Biomed Health Inform 2020;24:1899-906.

28. Mortara A, Vaira L, Palmieri V, et al. Would You Prescribe Mobile Health Apps for Heart Failure Self-care? An Integrated Review of Commercially Available Mobile Technology for Heart Failure Patients. Card Fail Rev 2020;6:e13.

29. Alharbi M, Straiton N, Gallagher R. Harnessing the Potential of Wearable Activity Trackers for Heart Failure Self-Care. Curr Heart Fail Rep 2017;14:23-9.
30. Granegger M, Schlöglhofer T, Ober H, et al. Daily life activity in patients with left ventricular assist devices. Int J Artif Organs 2016;39:22-7.

31. Schlöglhofer T, Robson D, Bancroft J, et al. International coordinator survey results on the outpatient management of patients with the HeartWare ${ }^{\circledR}$ ventricular assist system. Int J Artif Organs 2017;39:553-7.

32. Granegger M, Moscato F, Casas F, et al. Development of a pump flow estimator for rotary blood pumps to enhance monitoring of ventricular function. Artif Organs 2012;36:691-9.

33. Vollkron M, Schima H, Huber L, et al. Development of a suction detection system for axial blood pumps. Artif Organs 2004;28:709-16.

34. Vollkron M, Schima H, Huber L, et al. Advanced suction detection for an axial flow pump. Artif Organs 2006;30:665-70.

35. Naiyanetr P, Moscato F, Vollkron M, et al. Continuous assessment of cardiac function during rotary blood pump support: a contractility index derived from pump flow. J Heart Lung Transplant 2010;29:37-44.

36. Moscato F, Granegger M, Naiyanetr P, et al. Evaluation of Left Ventricular Relaxation in Rotary Blood Pump Recipients Using the Pump Flow Waveform: A Simulation Study. Artif Organs 2012;36:470-8.

37. Moscato F, Granegger M, Edelmayer M, et al. Continuous monitoring of cardiac rhythms in left ventricular assist device patients. Artif Organs 2014;38:191-8.

38. Granegger M, Schima H, Zimpfer D, et al. Assessment of aortic valve opening during rotary blood pump support using pump signals. Artif Organs 2014;38:290-7.

39. Hayward C, Lim CP, Schima H, et al. Pump Speed Waveform Analysis to Detect Aortic Valve Opening in Patients on Ventricular Assist Device Support. Artif Organs 2015;39:704-9.

40. Granegger M, Masetti M, Laohasurayodhin R, et al. Continuous Monitoring of Aortic Valve Opening in Rotary Blood Pump Patients. IEEE Trans Biomed Eng 2016;63:1201-7.

41. Noninvasive Diagnostics in Left Ventricular Assist Device Patients - Full Text View - ClinicalTrials.gov [Internet]. [cited 2020 Oct 13]. Available online: https://clinicaltrials. gov/ct2/show/NCT01981642

42. Orihashi K, Hong YW, Chung G, et al. New applications of two-dimensional transesophageal echocardiography in cardiac surgery. J Cardiothorac Vasc Anesth 1991;5:33-9.

43. Gross C, Schima H, Schlöglhofer T, et al. Continuous LVAD monitoring reveals high suction rates in clinically 
stable outpatients. Artif Organs 2020;44:E251-62.

44. Galand V, Flécher E, Auffret V, et al. Early Ventricular Arrhythmias After LVAD Implantation Is the Strongest Predictor of 30-Day Post-Operative Mortality. JACC Clin Electrophysiol 2019;5:944-54.

45. Berg DD, Vaduganathan M, Upadhyay GA, et al. Cardiac Implantable Electronic Devices in Patients With Left Ventricular Assist Systems. J Am Coll Cardiol 2018;71:1483-93.

46. Vollkron M, Voitl P, Ta J, et al. Suction events during left ventricular support and ventricular arrhythmias. J Heart Lung Transplant 2007;26:819-25.

47. Martina J, Jonge N, Rutten M, et al. Exercise hemodynamics during extended continuous flow left ventricular assist device support: The response of systemic cardiovascular parameters and pump performance. Artif Organs 2013;37:754-62.

48. Haft J, Armstrong W, Dyke DB, et al. Hemodynamic and exercise performance with pulsatile and continuous-flow left ventricular assist devices. Circulation 2007;116:I8-15.

49. Gross C, Marko C, Mikl J, et al. LVAD Pump Flow Does Not Adequately Increase With Exercise. Artif Organs 2019;43:222-8.

50. Arena R, Guazzi M, Myers J, et al. Prognostic value of heart rate recovery in patients with heart failure. Am Heart J 2006;151:851.e7-13.

51. Nanas S, Anastasiou-Nana M, Dimopoulos S, et al. Early heart rate recovery after exercise predicts mortality in patients with chronic heart failure. Int J Cardiol 2006;110:393-400.

52. Jung MH, Gustafsson F. Exercise in heart failure patients supported with a left ventricular assist device. J Heart Lung Transplant 2015;34:489-96.

53. Fresiello L, Jacobs S, Timmermans P, et al. Limiting factors of peak and submaximal exercise capacity in LVAD patients. PloS One 2020;15:e0235684.

54. Compostella L, Russo N, Setzu T, et al. Exercise

Cite this article as: Moscato F, Gross C, Maw M, Schlöglhofer T, Granegger M, Zimpfer D, Schima H. The left ventricular assist device as a patient monitoring system. Ann Cardiothorac Surg 2021;10(2):221-232. doi:10.21037/acs-2020-cfmcs-2 18
Performance of Chronic Heart Failure Patients in the Early Period of Support by an Axial-Flow Left Ventricular Assist Device as Destination Therapy. Artif Organs 2014;38:366-73.

55. Gross C, Fresiello L, Schlöglhofer T, et al. Hemodynamic exercise responses with a continuousflow left ventricular assist device: Comparison of patients' response and cardiorespiratory simulations. PLoS One 2020;15:e0229688.

56. Slaughter MS, Ising MS, Tamez D, et al. Increase in circadian variation after continuous-flow ventricular assist device implantation. J Heart Lung Transplant 2010;29:695-7.

57. Consolo F, Esposti F, Gustar A, et al. Log files analysis and evaluation of circadian patterns for the early diagnosis of pump thrombosis with a centrifugal continuous-flow left ventricular assist device. J Heart Lung Transplant 2019;38:1077-86.

58. Jorde UP, Aaronson KD, Najjar SS, et al. Identification and Management of Pump Thrombus in the HeartWare Left Ventricular Assist Device System: A Novel Approach Using Log File Analysis. JACC Heart Fail 2015;3:849-56.

59. Bunge JJH, den Uil CA, Constantinescu AC, et al. Acute Pump Thrombosis in the Early Postoperative Period After HeartMate 3 Implantation. ASAIO J 2019;65:e72-4.

60. Grabska J, Schlöglhofer T, Gross C, et al. Early Detection of Pump Thrombosis in Patients With Left Ventricular Assist Device. ASAIO J 2020;66:348-54.

61. Hohmann S, Veltmann C, Duncker D, et al. Initial experience with telemonitoring in left ventricular assist device patients. J Thorac Dis 2019;11:S853-63.

62. Ahmed MN, Toor AS, O’Neil K, et al. Cognitive Computing and the Future of Health Care Cognitive Computing and the Future of Healthcare: The Cognitive Power of IBM Watson Has the Potential to Transform Global Personalized Medicine. IEEE Pulse 2017;8:4-9. 